\title{
A NEW BEE OF THE GENUS HERIADES FROM PANAMA (HYMENOPTERA, MEGACHILIDÆ)
}

\author{
By Charles D. Michener
}

\section{American Museum of Natural History, New York City}

The bees of the genus Heriades are primarily confined to North America, Eurasia, and Africa. In the western hemisphere the most southern known species has been Heriades bruneri Titus from Costa Rica. It is therefore of interest to find in the collection of the American Museum of Natural History a distinct new Panamanian species of this genus.

\section{Heriades (Neotrypetes) currani new species}

Female: Length $51 / 2 \mathrm{~mm}$. Pubescence white. Labrum with one basal tubercle; mandible with two longitudinal carinæ, lower one extending from apex nearly to base and somewhat elevated about three-fifths of distance from apex to base, upper extending about half way from apex to base and terminating basally in a low transverse elevation, distance between first and second mandibular teeth about one-half distance between second and third; malar area below and behind produced to an angle; clypeus with apical margin subtruncate, with a pair of small premarginal tubercles separated from one another by less than basal width of clypeus; surface of clypeus evenly convex, punctation of apical portion fine and dense, of basal portion as coarse as that of supraclypeal area; punctation of vertex and mesepisterna slightly finer than that of mesoscutum and mesoscutellum; base of propodeum with the usual transverse row of very large depressions; wings slightly dusky; abdominal terga middorsally with punctures separated by slightly less than their diameters, somewhat coarser on posterior than on anterior segments, terga one to five with apical fasciæ of white pubescence.

Male: Length $5 \mathrm{~mm}$. Similar to female. Shortest distance between eyes slightly more than half length of eye; first flagellar segment nearly twice as broad as long; outer margin of mandible straight basally seen from front; labrum with basal raised 
area; abdominal terga more closely punctured than in female, abruptly more coarsely punctured on third and following terga than on first two, punctures contiguous on posterior terga; profile of sixth tergum slightly elevated apically; first abdominal sternum with posterior margin rounded, in profile with gentle convexity about two-thirds of its length from base to apex; fifth

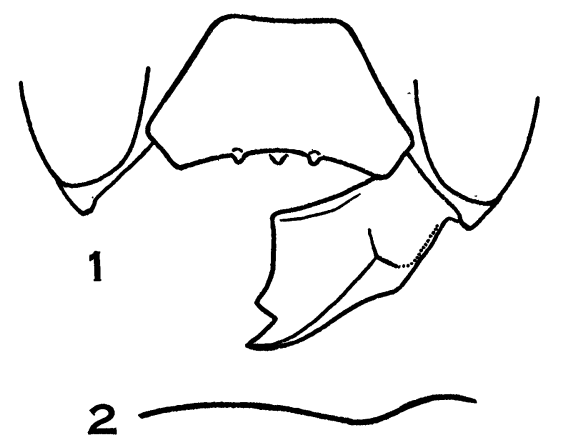

Fig. 1, Lower part of face of female Heriades currani, one mandible omitted; Fig. 2, Profile of first abdominal sternum of male Heriades currani, base at left.

sternum with an acutely pointed median process laterad of which lie the usual rows of long capitate hairs; sixth sternum but little down-curved at apex, subapical hairs rather numerous and long, extending beyond margin of sternum.

Holotype female, Panama, Republic of Panama, February to March, 1915; allotype male, Patilla Point, Canal Zone, Panama, January 15, 1929, collected by Dr. C. H. Curran after whom this species is named. Both specimens are in the collection of The American Museum of Natural History.

In the revision of American Heriades (Michener, 1938, Ann. Ent. Soc. Am., 31: 514-531) this species runs clearly to the subgenus Neotrypetes. In the key to the species of that subgenus the male runs best to leavitti Crawford, a form differing from currani by the dark wings, longer first flagellar segment, etc. The female as well as the male seems most closely related to $H$. crucifera Cockerell from New Mexico and Arizona, although because of the proximity of the premarginal tubercles of the clypeus it will not run to that species in the key. It differs further from crucifera by the less strongly angular malar area, the somewhat differently arranged carinæ near the bases of the 
mandibles, etc. From $H$. bruneri Titus, the species geographically closest to currani, the latter differs by its coarsely punctate abdomen and white rather than yellow pubescence. Like $H$. texana Michener, and unlike other species, currani has an elevation on the ventral mandibular carina of the female, but it is not nearly so conspicuous as in texana. 

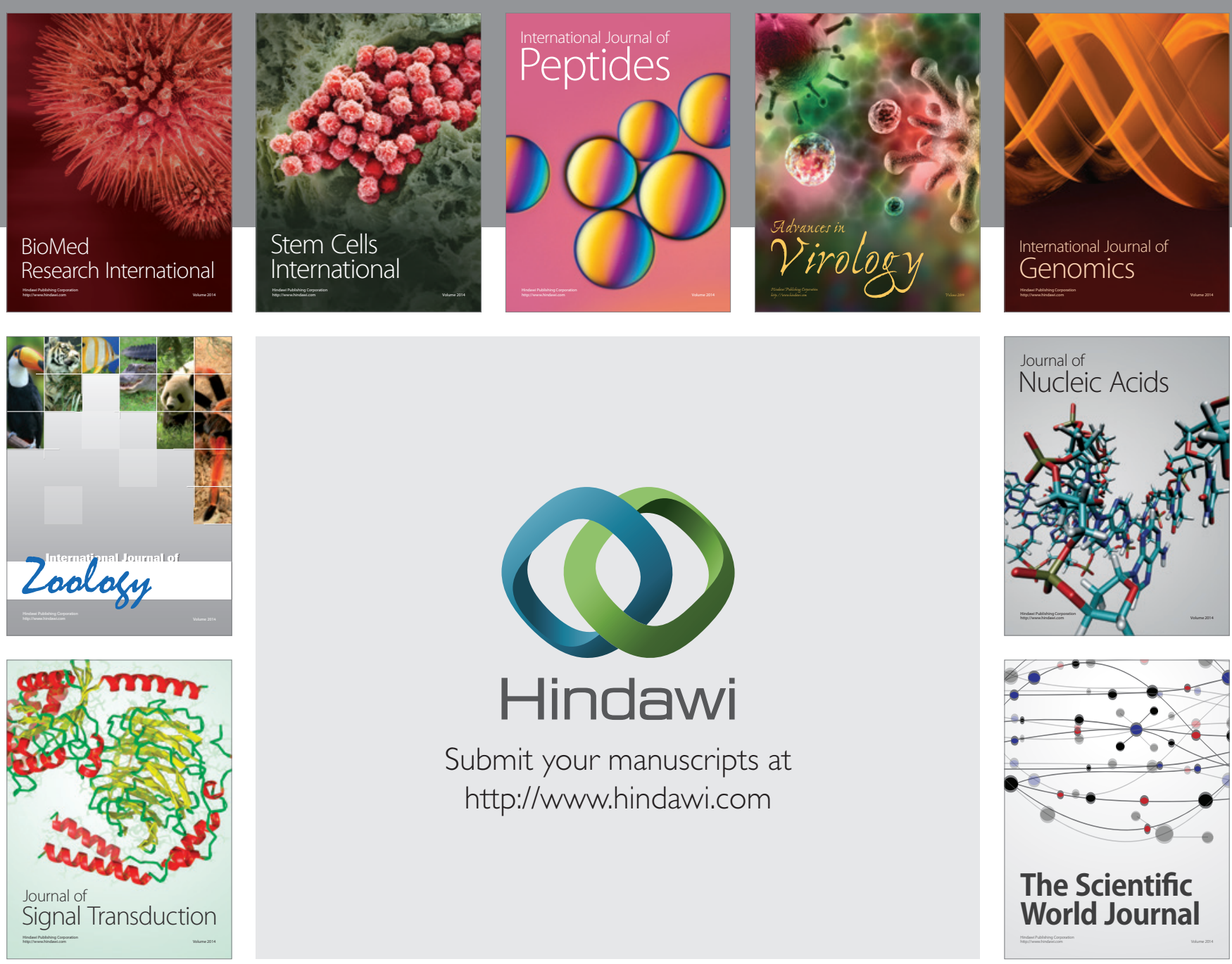

Submit your manuscripts at

http://www.hindawi.com
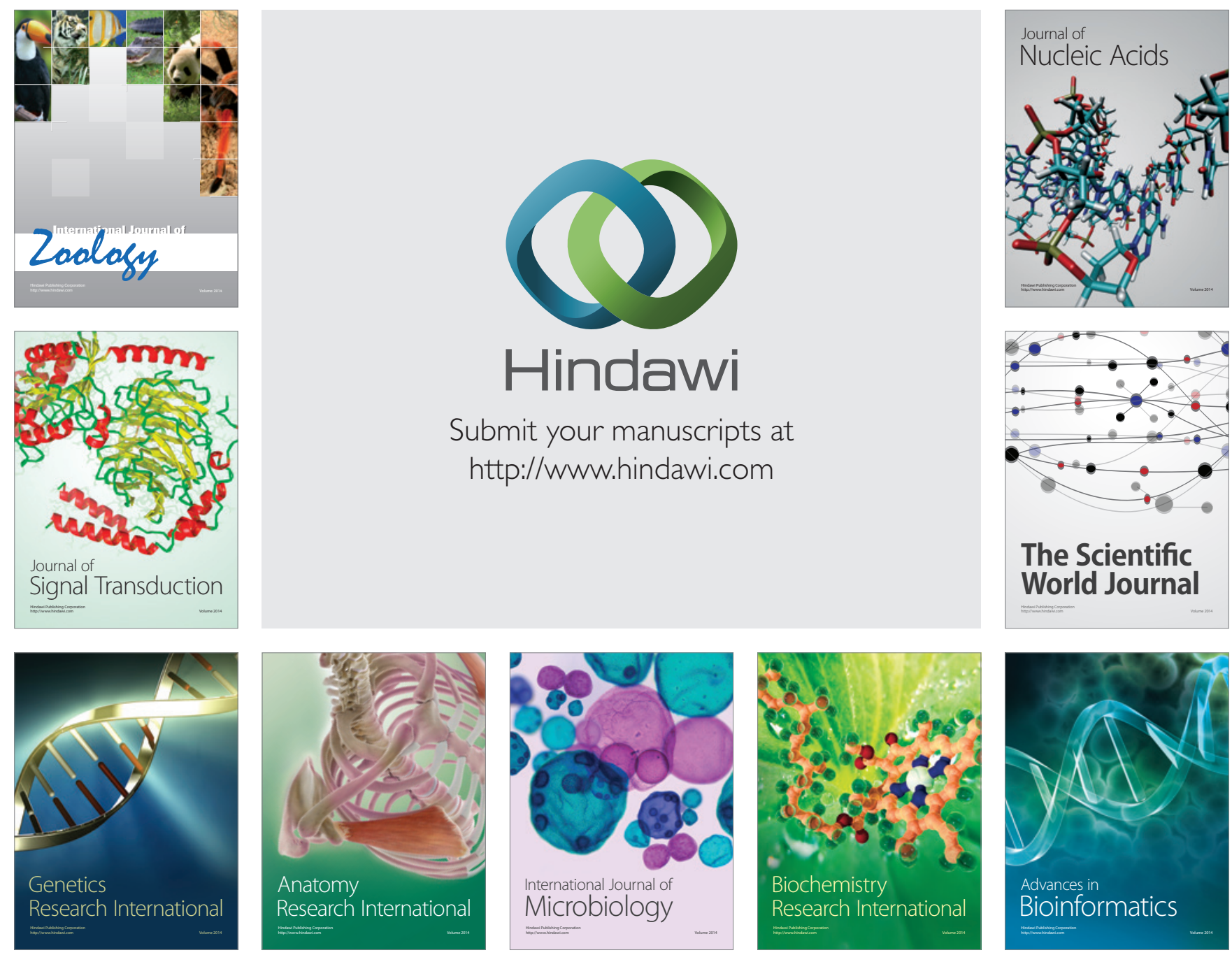

The Scientific World Journal
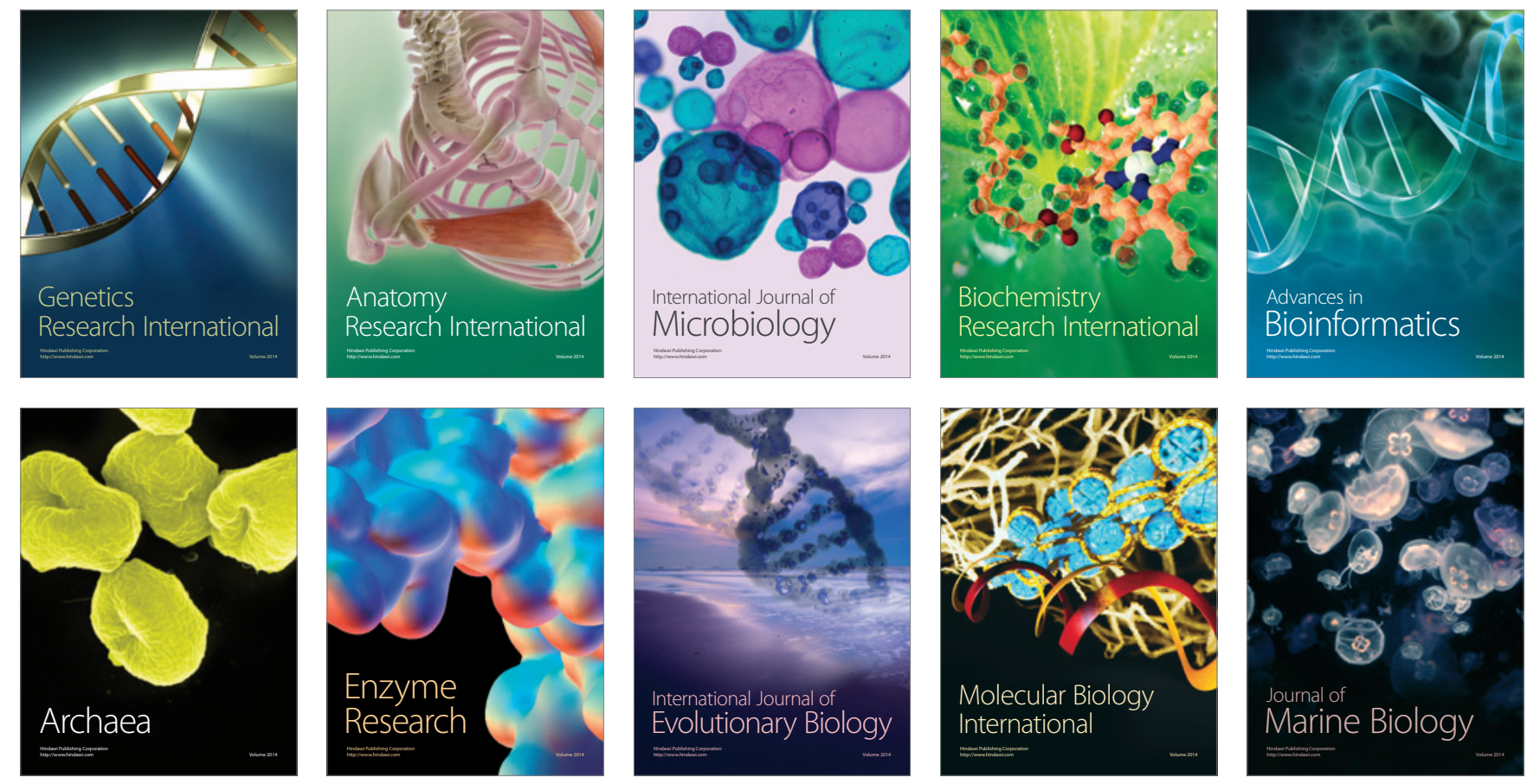